Journal of

Dentistry and Oral Health

\title{
ISW for the Treatment of Bilateral Posterior Buccal Crossbite
} Chun-Shuo HUANG ${ }^{1,2}$, Chien-Chih $\mathrm{YU}^{3,{ }^{3}}$, Jian-Hong YU ${ }^{1,2}$, and Yuan-Hou CHEN ${ }^{1}$

${ }^{1}$ Department of Orthodontics, China Medical University Hospital, Taichung, Taiwan

${ }^{2}$ School of Dentistry, College of Dentistry, China Medical University, Taichung, Taiwan

${ }^{3}$ School of Pharmacy, China Medical University, Taichung, Taiwan

*Corresponding author: Chien-Chih YU, School of Pharmacy, China Medical University, Taichung, Taiwan; Email: kenkoyu@ hotmail.com

Received Date: August 22, 2018; Accepted Date: September 27, 2018; Published Date: September 29, 2018

Citation: Chun-shuoHUANG (2018) ISW for the Treatment of Bilateral Posterior Buccal Crossbite. J Dent Oral Health 5: 1-6.

\begin{abstract}
The objective of the treatment is for the adult patient with bilateral posterior buccal crossbite by ISW (Improved Super-elastic Ti-Ni alloy wire, developed by Tokyo Medical and Dental University). An adult patient (20 years old) came to our clinic with a chief complaint of bilateral posterior buccal crossbite and not being able to chew food well. Clinical examination revealed bilateral posterior buccal crossbite. We extract \#18 and \#48 to facilitate the correction of posterior buccal crossbite. With successful molar up righting by bracket upside-down (b-u-d), adding torque on the archwire, the posterior buccal crossbite was corrected efficiently. The total treatment was completed within 7 months and the patient was satisfied with the outcome.

Keywords: ISW, skeletal Class II, buccoversion, bracket upside-down(b-u-d), crown buccal torque, intermaxillary elastics, ISW MEAW technique
\end{abstract}

\section{Introduction}

Treatment of posterior crossbite is considered one of the most common problems in orthodontics. [1-7] when an arch-length discrepancy exists in the posterior segments, the mandibular second molars erupt lingually producing a posterior crossbite, or a scissors-bite. In patients with bilateral posterior crossbites, the buccal cusps of the maxillary teeth occlude to the lingual of the buccal cusps of the corresponding mandibular teeth on both sides. Both dental and skeletal factors contribute to development of posterior crossbite [8-10]. In this case, bilateral dental posterior buccal crossbite will be discussed and the treatment was completed efficiently without conventional fixed orthodontic appliances or bite plate due to the fact that those appliances sometimes incur inconvenience and patients' discomfort.

\section{History and Diagnosis}

The 20 y/o male complained about posterior buccal crossbite and not being able to chew food well. Hislateral profile was convex, and the frontal view showed slightly facial asymmetry phenomenon (Figure 1). Clinical examination revealed bilateral Class IIItendency ofmolar relationship, bilateral canine class I relationship, bilateral upper second molar buccoversion and lingually tipped mandibular molar region (Figure 2). Panoramic film showed \#18, \#48 existence (Figure 3).
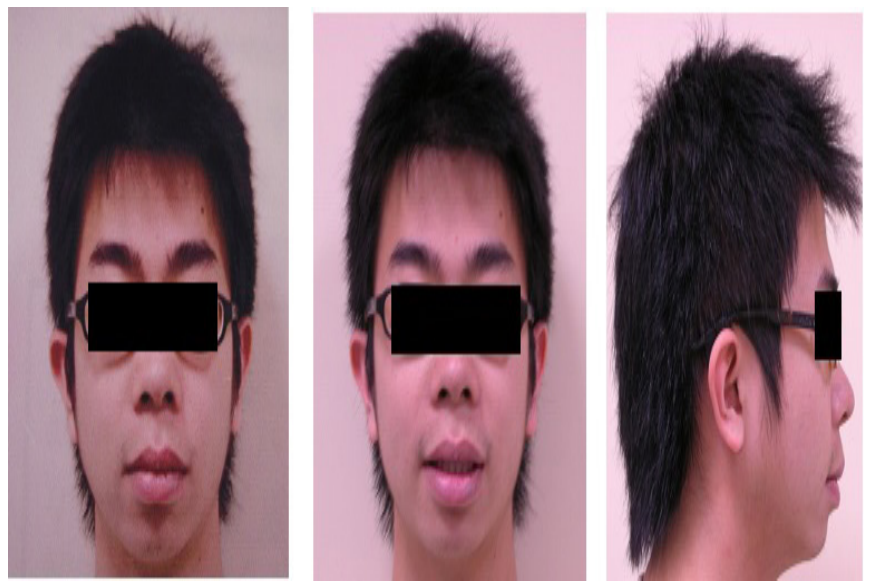

Figure 1: Facial photos before active treatment 


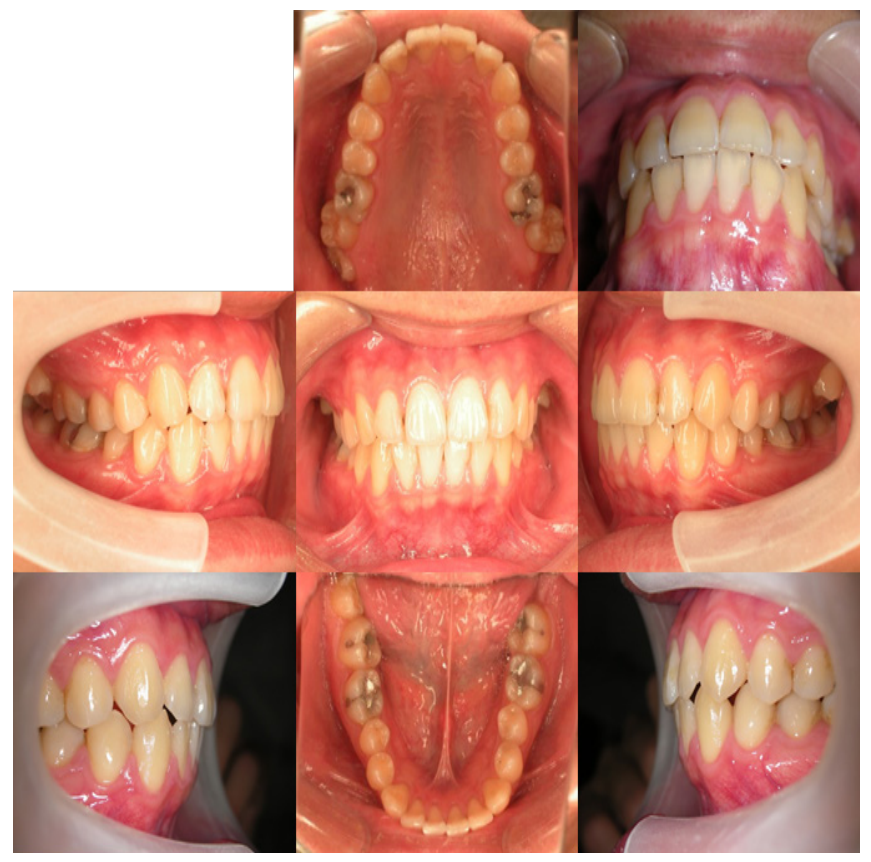

Figure 2: Intraoral photos before active treatment

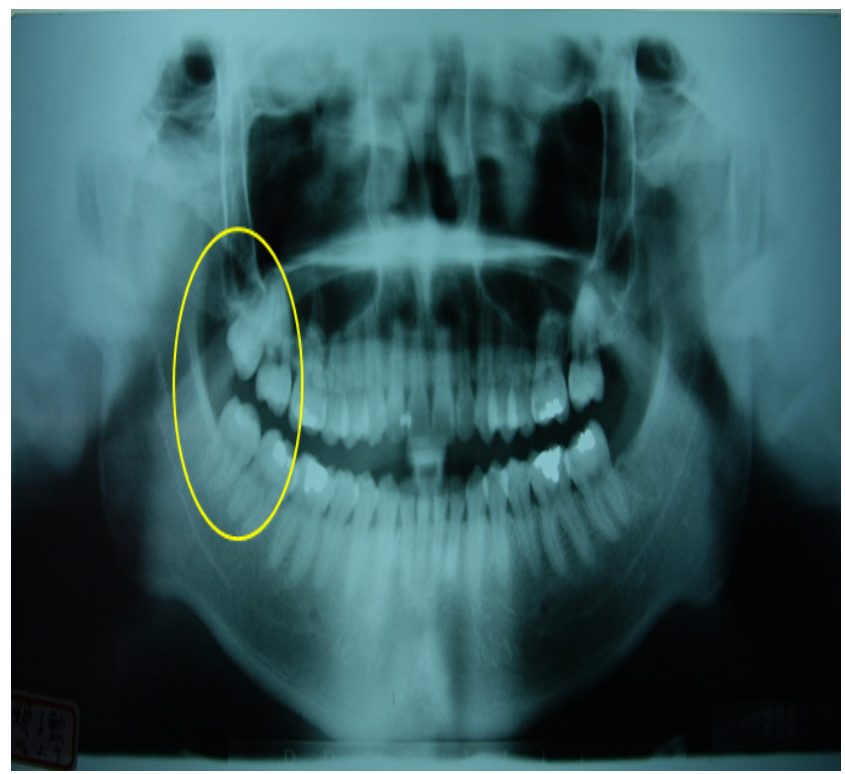

Figure 3: Panoramic film before active treatment

The radiographic methods of the research include intraoral photos, lateral cephalometric projection and panoramic $\mathrm{x}$-ray films. Also the cephalometric analyses before and after the treatment were presented in this case. The cephalometric analysis showed a skeletal class II tendency jaw relationships (SNA:89.0 ${ }^{\circ} \mathrm{SNB}: 84.0^{\circ} \mathrm{ANB}: 5.0^{\circ}$ ) and dental compensation (U1 to SN plane: $111.2^{\circ}$ interincisal angle: $119.0^{\circ}$ ). The low angle skeletal pattern can be seen prominently in the polygon (Gonial angle:113.3 ${ }^{\circ}$ ) (Figure 4, Figure 5).
Therefore, the summary of diagnosis includes:

1. Functional (-)

2. Skeletal $( \pm): \mathrm{SNA}: 89.0^{\circ} \mathrm{SNB}: 84.0^{\circ} \mathrm{ANB}: 5.0^{\circ}$

3. Denture(+): U1 to SN plane: $111.2^{\circ}$

4. Dental (-)

5. Discrepancy(+):Upper: R't: $0.0 \mathrm{~mm} /$ L't: $-0.5 \mathrm{~mm}$ Lower: R't: $-0.5 \mathrm{~mm} / \mathrm{L't}$ : $-0.5 \mathrm{~mm}$
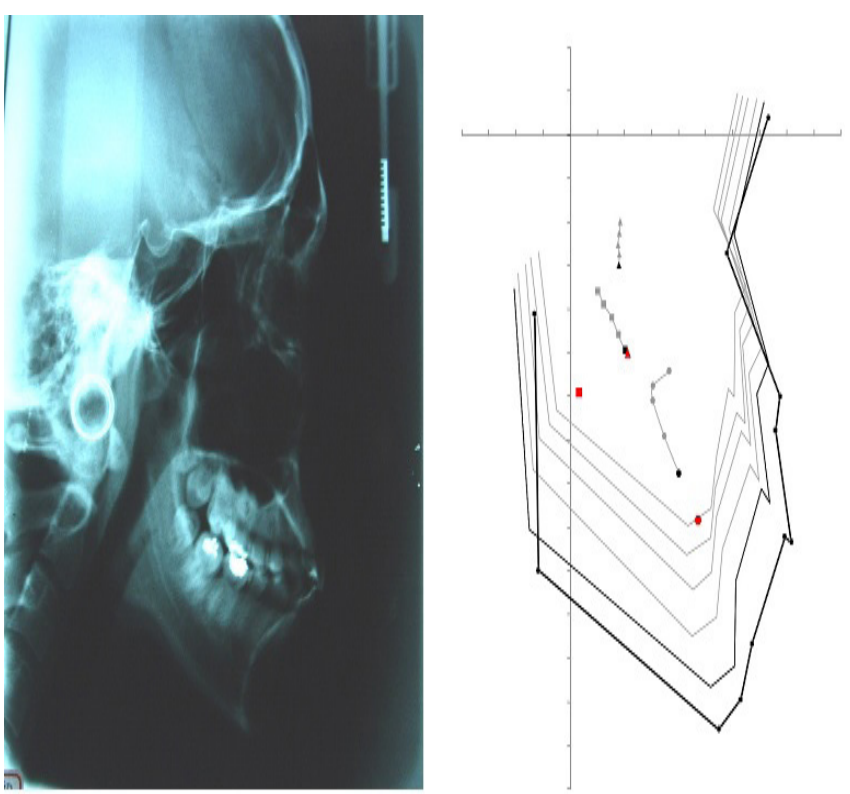

Figure 4: Lateral cephalometric film before active treatment

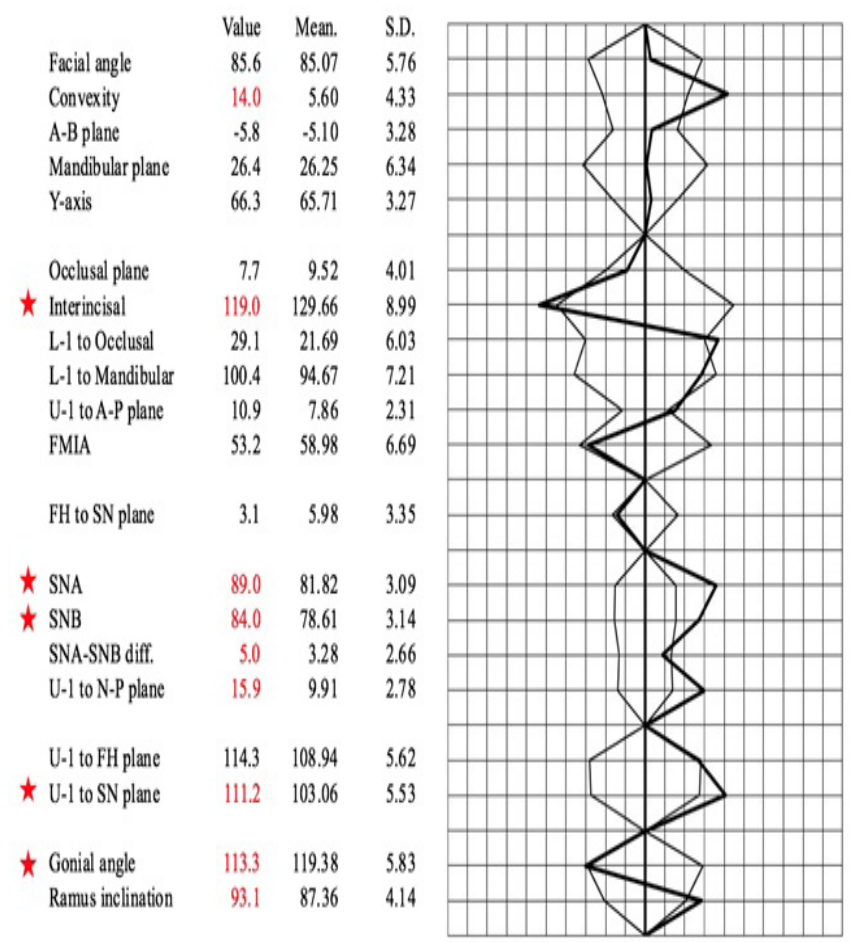

Figure 5:Polygon before active treatment 


\section{Treatment Objectives}

Our treatment objectives were (1) to remove functional interference over bilateral maxillary second molar regions, (2) to improve facial profile, (3) to establish appropriate overbite, overjetand arch coordination, (4) to establish indivualized occlusion

Due to the fact that the patient strongly refused the possibility of orthognathic surgery. Therefore, treatment plan includes:

1. \#18, \#48 extraction

2. Full mouth DBS

\section{Treatment Progress}

Treatment was started from 2007.04.06 with full mouth DBS and leveling with 0.016 x 0.022 ISW (Figure.6).

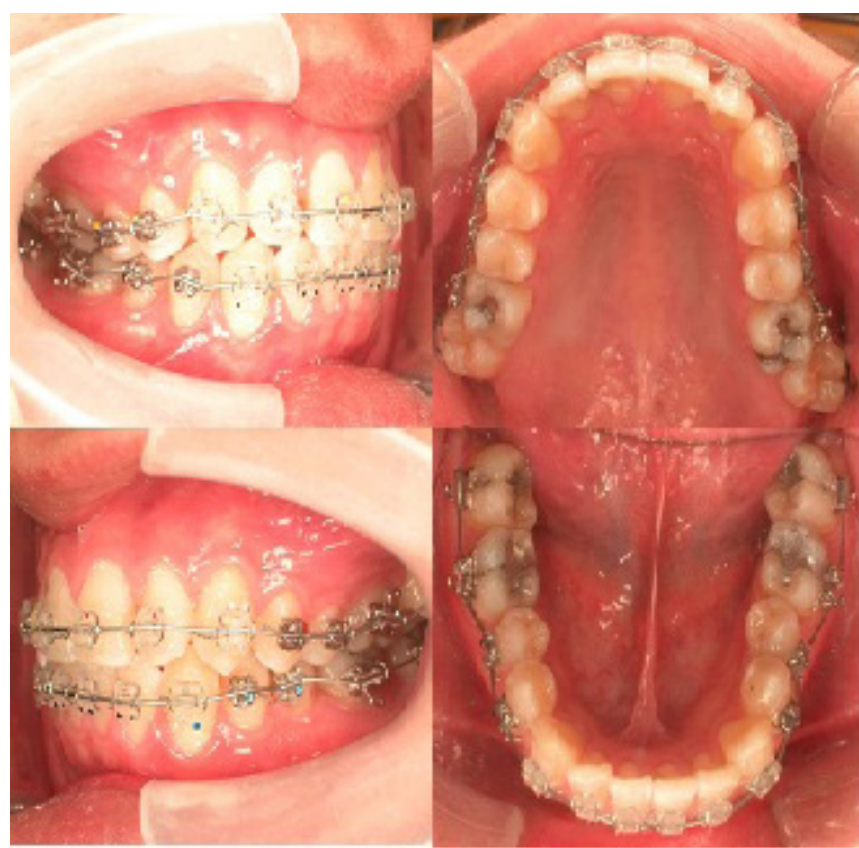

Figure 6: Period of active treatment: 0 month

On 2007.05.04. after one month of active treatment, for bite opening, \#37, \#47 were re-bonded upside down and \#17, \#27 crown lingual torque and transpalatal IME (5/16M) was added. (Figure.7)

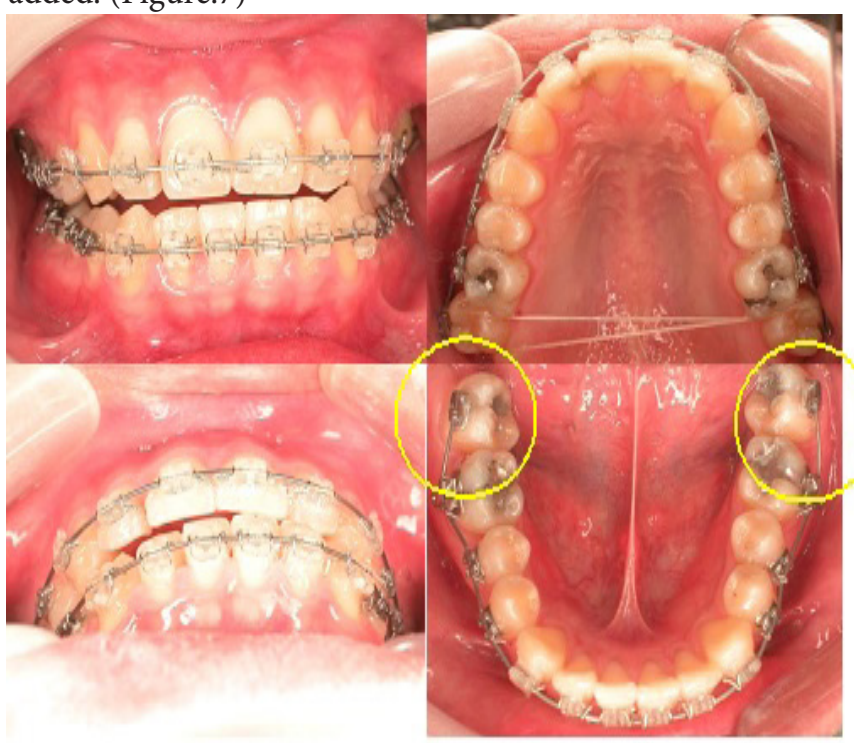

Figure 7: Period of active treatment:1 month
On 2007.06.11, for better torque control of \#17, \#27 region, reinforced crown lingual torque and Trans palatal IME were performed and \#37, \#47 crown buccal torque was added (Figure.8).

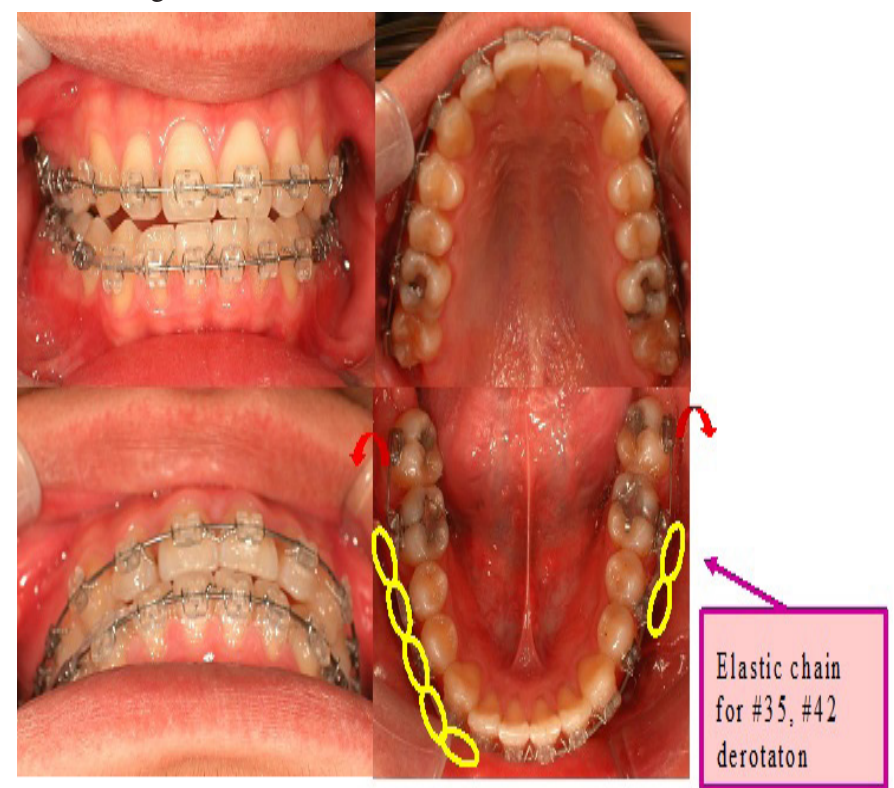

Figure 8: Period of active treatment: 2 months

On 2007.07.13, after 3 months of active treatment, intermaxillary elastics $(3 / 16 \mathrm{M})$ were added to facilitate bite control, and at the same time, for midline adjustment (Figure.9).

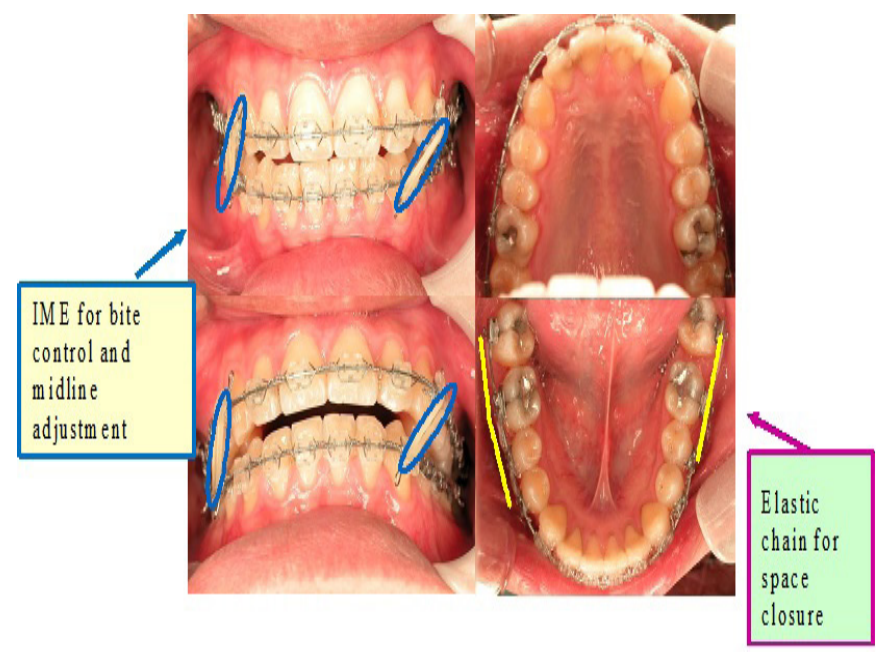

Figure 9:Period of active treatment: 3 months

\section{Treatment Result}

After 5 months of active treatment, on 2007.09.07, IME and elastic chain were used for space closure and better cusp interdigitation (Figure.10). 


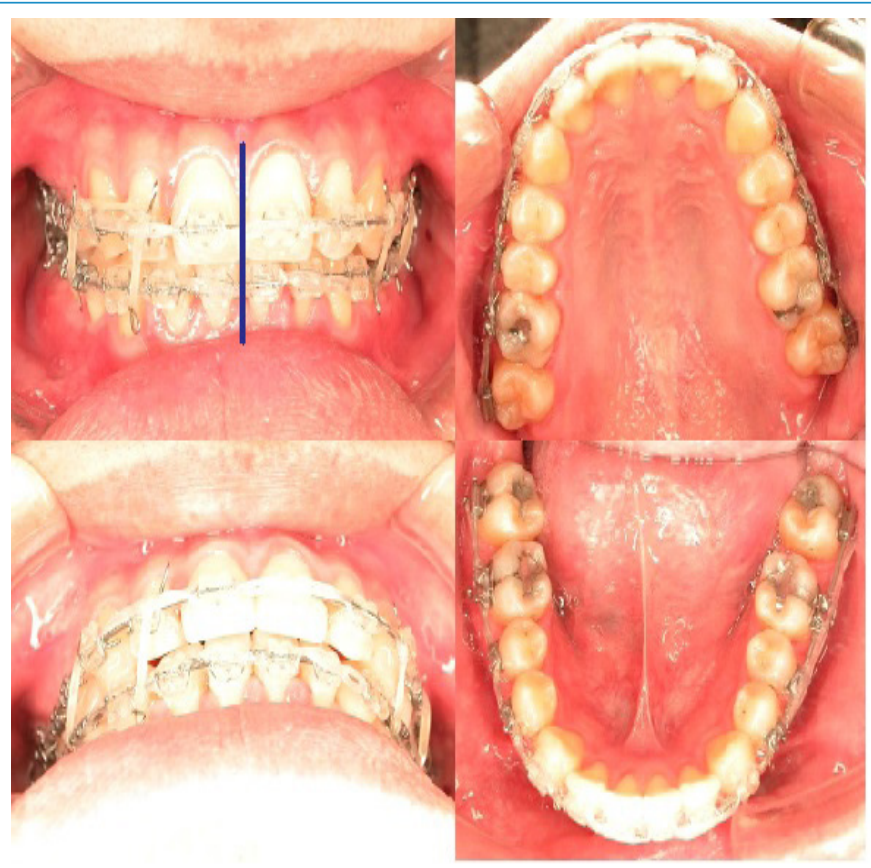

Figure 10: Period of active treatment:5 months

On 2007.11.26, debonding of full mouth bracket was performed and circumferential retainer was delivered for the upper arch and Hawley retainer for the lower (Figure.11).

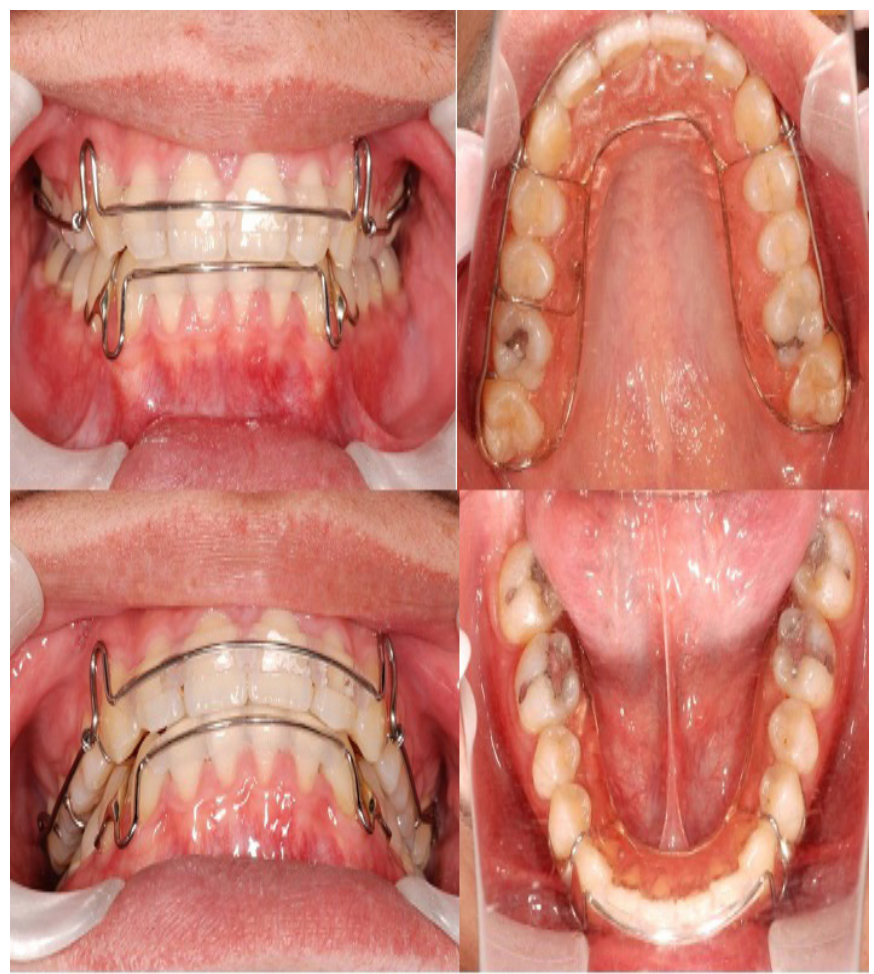

Figure 11: Period of active treatment: 7 months

For the total treatment time of 7 months, a stable occlusion was achieved and esthetic appearance was improved after the treatment (Figure. 12\&13).
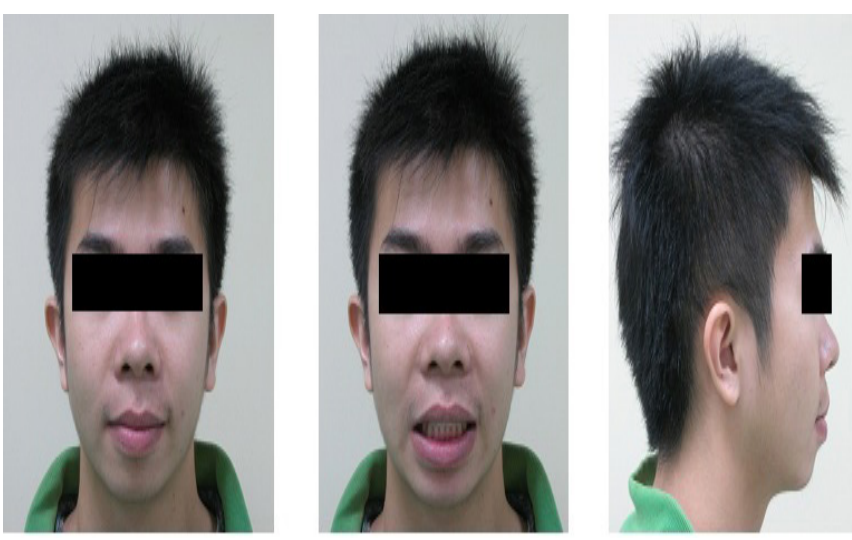

Figure 12: Facial photos after active treatment

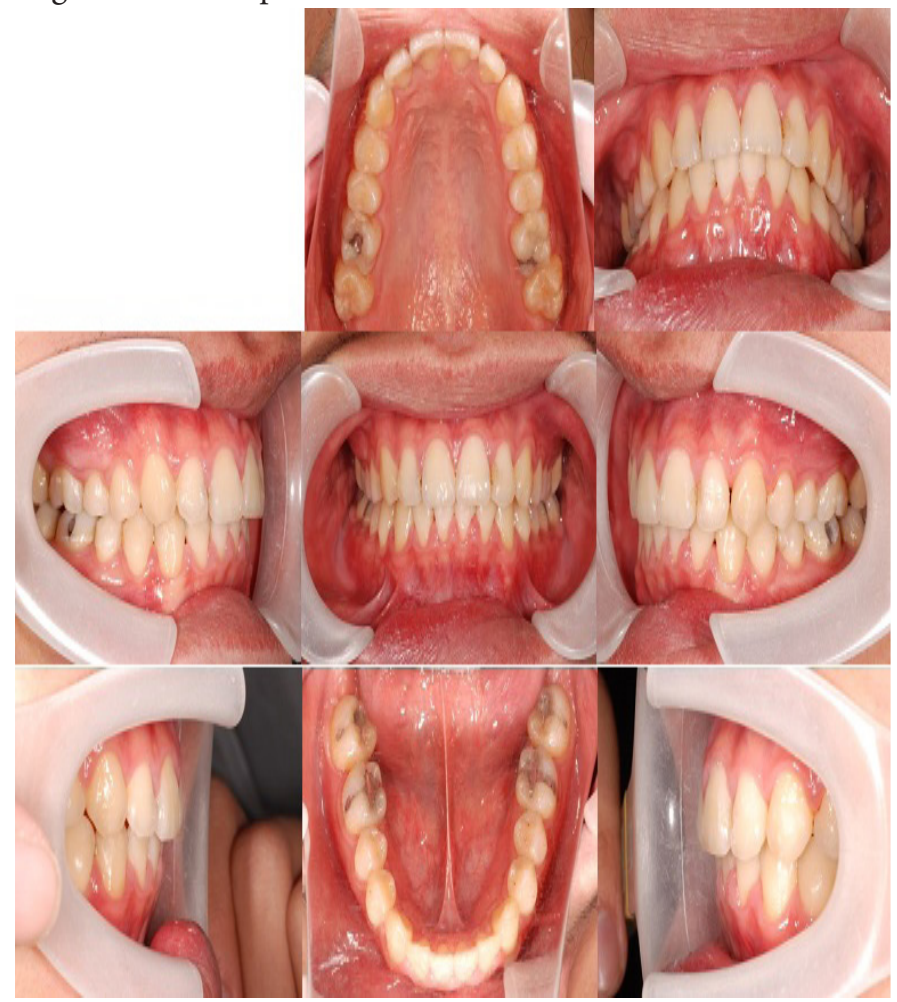

Figure 13: Intraoral photos after active treatment

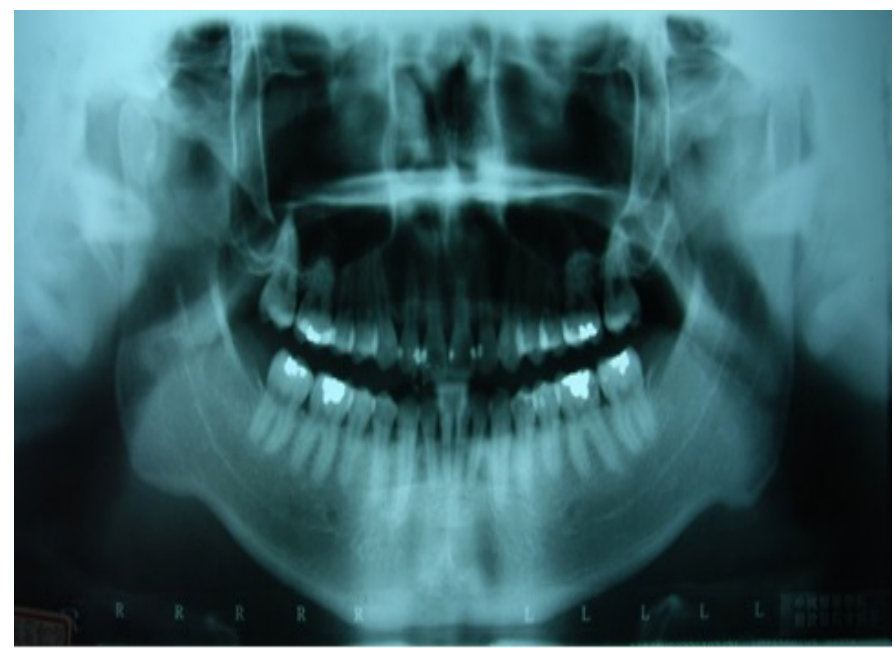

Figure 14: Panoramic film after active treatment 

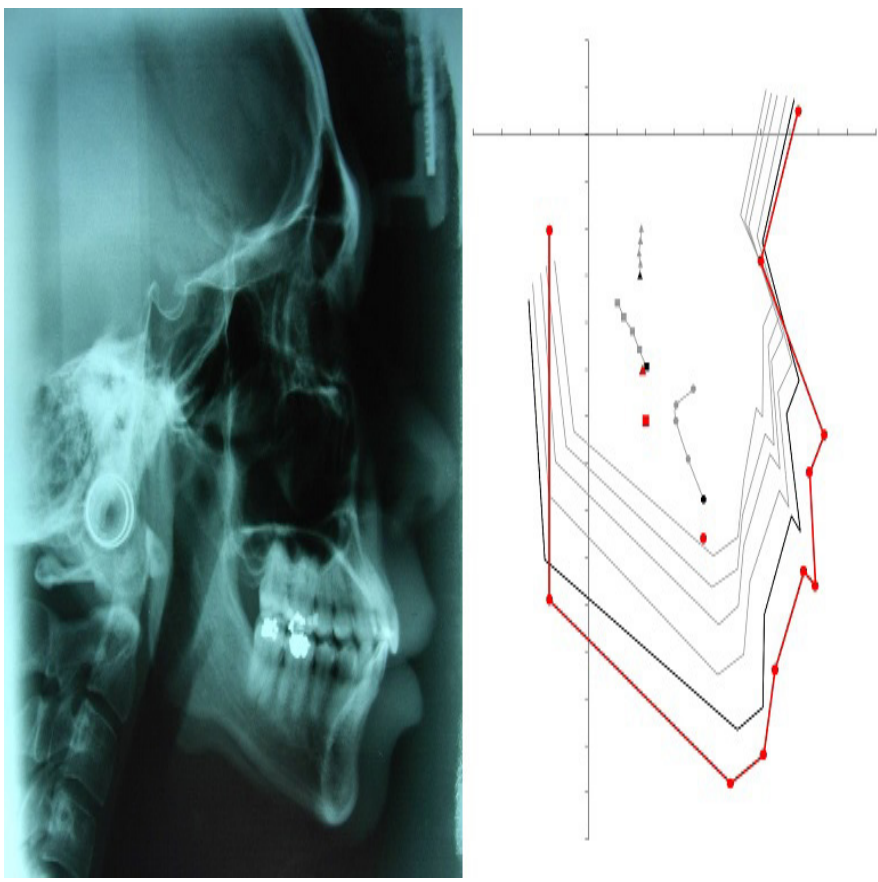

Figure 15:Lateral Cephalometric film after active treatment

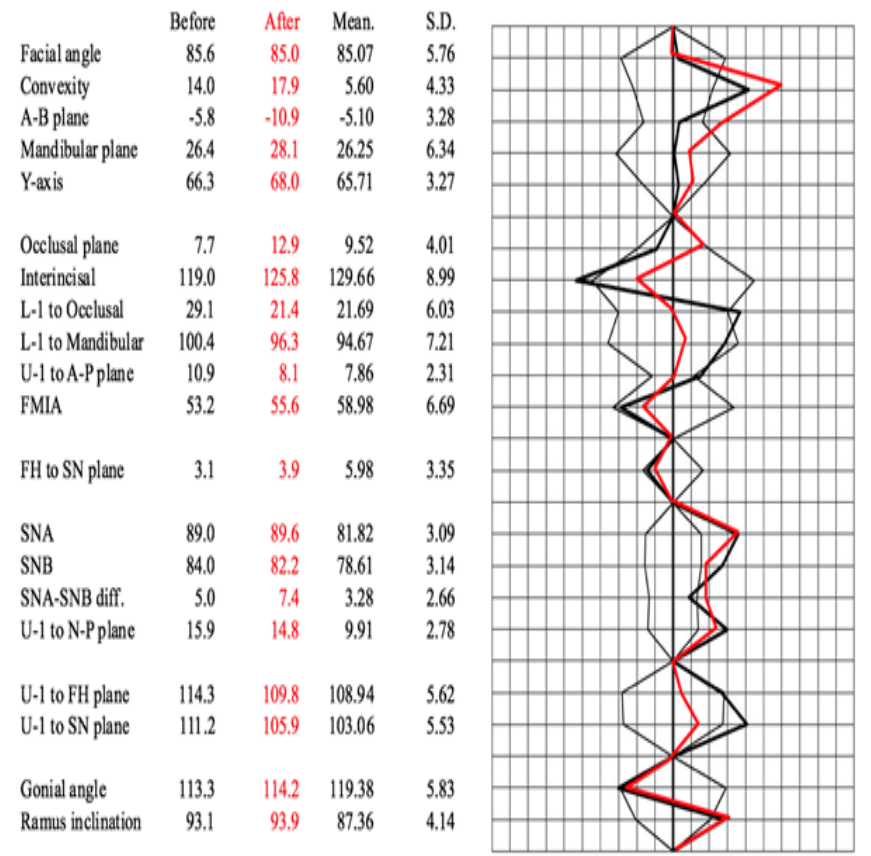

Figure 16: Polygon after active treatment

After 7 months period of orthodontic active treatment, lateral cephalometric projection and panoramic x-ray films was taken, polygon and superimposition after active treatment was analyzed and denture pattern improved prominently (U1 to $\mathrm{SN}$ plane: $111.2^{\circ}->105.9^{\circ}$ interincisal angle: $\left.119.0^{\circ}->125.8^{\circ}\right)$ (Figures. 14-17).

\section{Superimposition (1)}

- Superimposed on SN plane at S.

- 20y03m before

- 2ly00m after

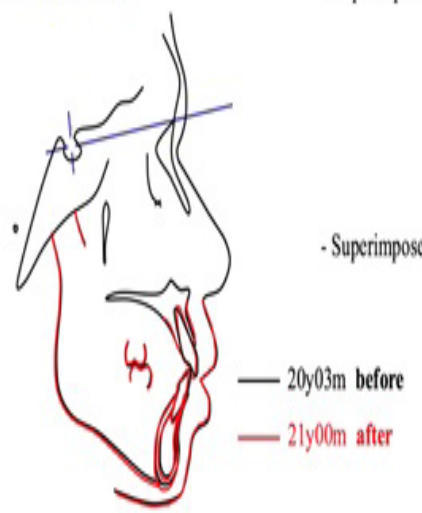

\section{Superimposition (2)}

Superimposed on Palatal plane at ANS.

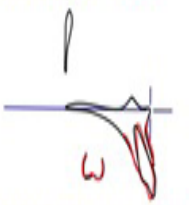

crimposed on Mandibular plane at Me.

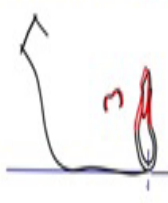

Figure 17: Superimposition after active treatment

\section{Discussion}

Treatment of posterior buccal crossbite case is a challenging scope of orthodontics. [11-13] sometimes, we have to use a bite plate for bite opening and cross elastics to correct the posterior buccal crossbite. However, with ISW treatment and reverse torque by bracket upside-down, correction of posterior buccal crossbite becomes much easier and we can avoid imposing too much inconvenience and discomfort on the patients. After 7 months of active treatment, a desirable outcome was achieved. Therefore, posterior buccal crossbite can be treated with ISW combined with a favorable torque control.

\section{Buccoversion correction}

There are many methods to help correct buccoversions, such as bite plate, cross-elastics, transpalatal-arch with extension hooks, TADs, etc. However, those appliances sometimes incur inconvenience and patients' discomfort.In this case, we used the super-elasticity of ISW and intermaxillary elastics to level the buccosversions (Figure.18)

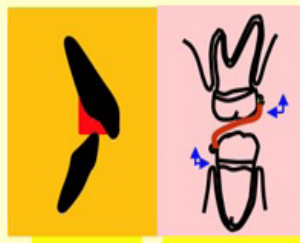

Bite plate Cross-elastics

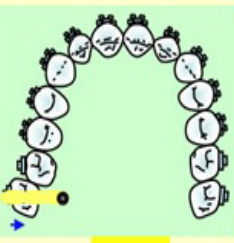

TADs

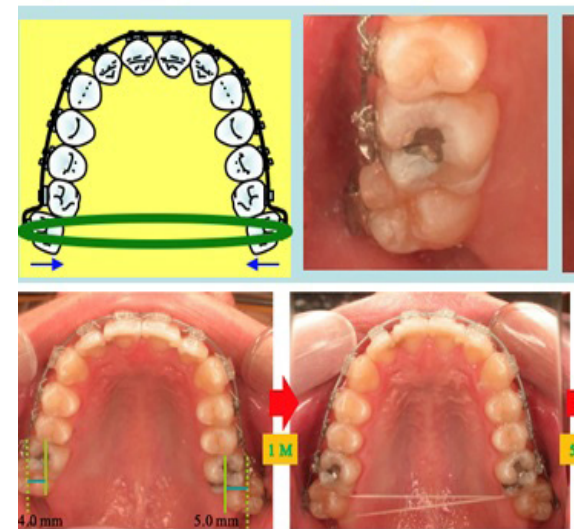

Figure 18: Buccoversion correction

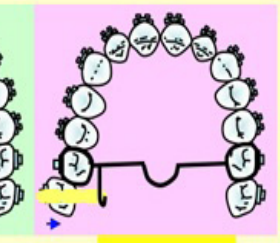

TPA + hooks

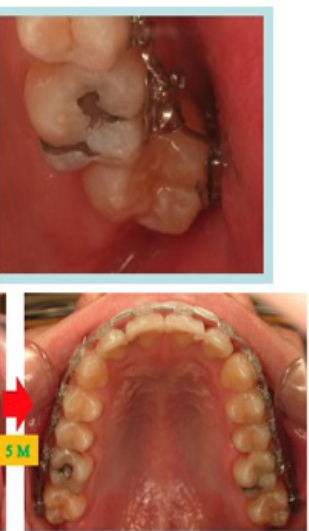




\section{Linguoversion correction}

There are many methods to help correct linguoversions, such as bite plate, cross-elastics, TADs, etc. However, those appliances sometimes incur inconvenience and patients' discomfort.In this case, we used some methods to change lower 2nd molars torque so as to correct linguoversion (Figure.19).

(1) Bracket upside down (B-U-D)

(2) Add crown buccal torque over ISW by heat bender

(3) Use upper molar tubes instead, eg. \#17 for \#37

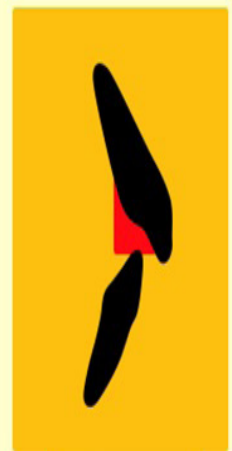

Bite plate

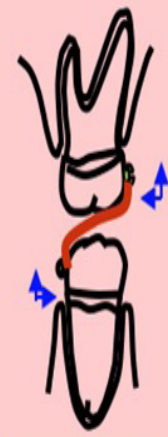

Cross-elastics

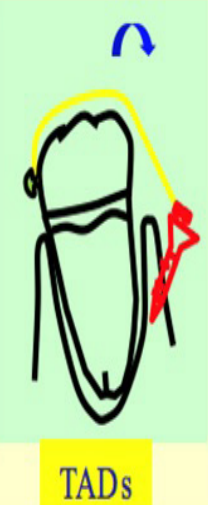

Rembve hook to prevent oodusal intefferexe
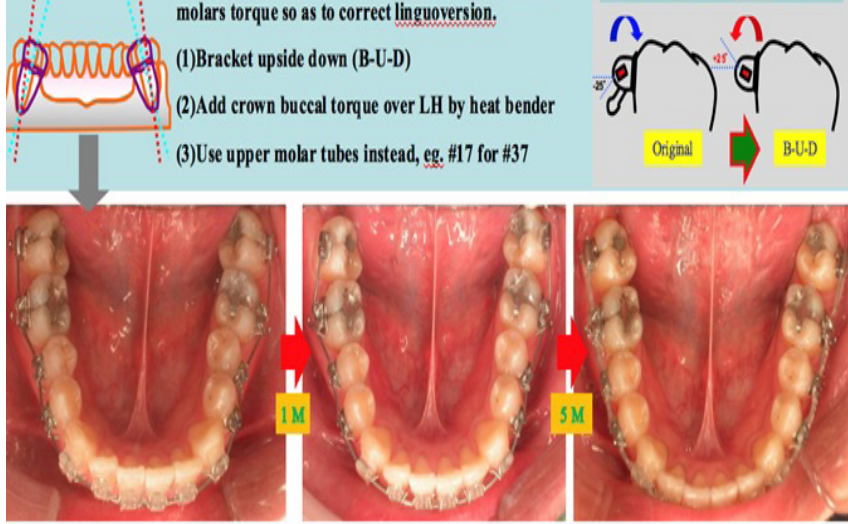

Figure 19: Linguoversion correction

\section{Overbite control}

Bite opening often takes place during scissors bite correction. In this case, we used intermaxillary elastics and elastic chain to control the overbite. In addition, the patient's occlusion gradually settling down also benefit the overbite control. If not the case, we can also use ISW MEAW and intermaxillary elastics to control the bite opening problem (Figure.20).

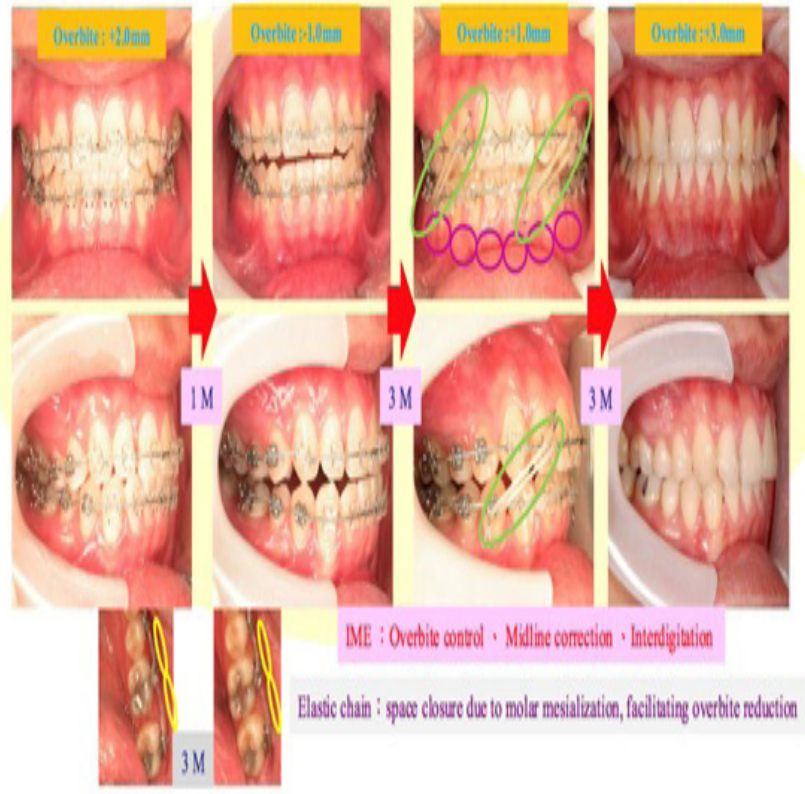

Figure 20: Overbite control

\section{Transitional bite opening}

During the orthodontic treatment, we may sometimes find transitional bite opening. In some situations, bite opening is inevitable (eg, during posterior buccal crossbite correction). However, in others, bite opening is intentional procedure (eg, during anterior crossbite correction). When transitional bite opening occurs, what we have to do first is keep close observation on the reasons, and then, eliminate possible occlusal interferences. We can use ISW MEAW and intermaxillary elastics to facilitate overbite increase (Figure.21).

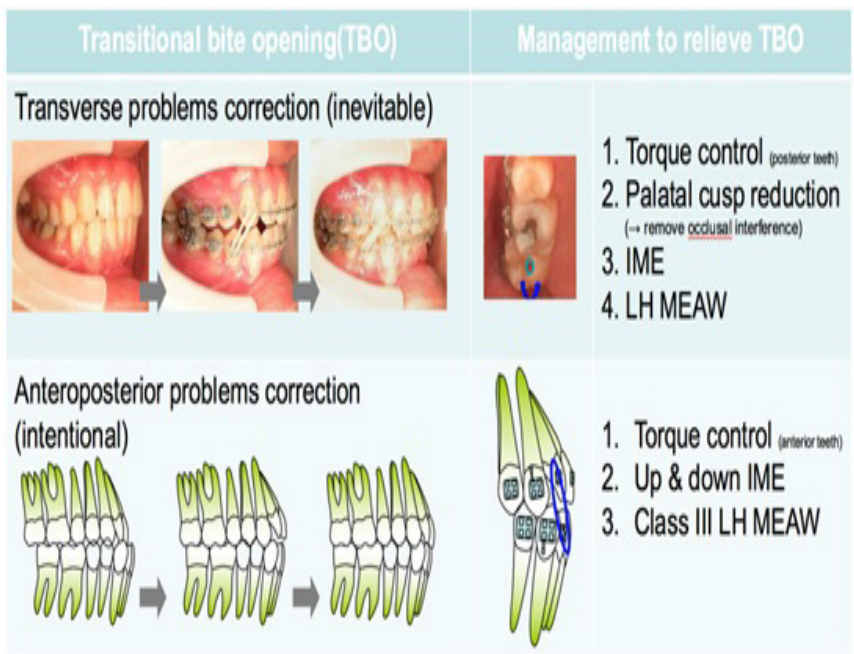

Figure 21: Transitional bite opening 


\section{Retention}

We can use either removable retainers or fixed retainers to maintain the treatment result. In this case, the reason why we chose removable retainers rather than fixed was because fixed retainers could be apt to damage, loosening, difficulty in keeping oral hygiene, etc. In terms of removable retainers, a wraparound design enveloping the corrected 2nd molars is essential to prevent them from rolling out (relapse) (Figure.22).
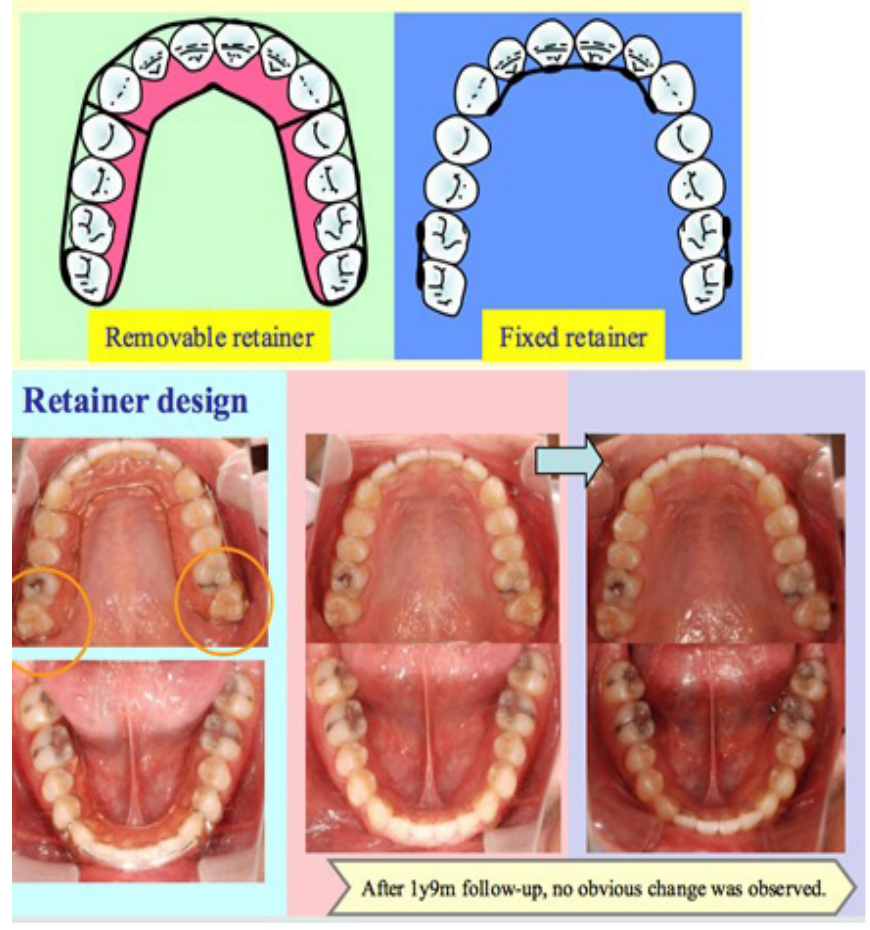

Figure 22: Retention

\section{Conclusion}

Treatmentfor the adult patient with bilateral posterior buccal crossbite by ISW (Improved Super-elastic Ti-Ni alloy wire, developed by Tokyo Medical and Dental University) was discussed in the article. With successful molar up righting by bracket upside-down (b-u-d), adding torque on the archwire, the posterior buccal crossbite was corrected efficiently.

After 7 months of active treatment, a normal occlusion and a desirable cusp interdigitation were achieved. Therefore, adult bilateral posterior buccal crossbite can be treated with ISW treatment.

\section{References}

1. Thilander B, Pena L, Infante C, Parada SS, de Mayorga C. (2001) Prevalence of malocclusion and orthodontic treatment need in children and adolescents in Bogota, Colombia. An epidemiological study related to different stages of dental development. Eur J Orthod 23:153-1S67.

2. Thilander B, Lennartsson B. (2002) Study of children with unilateral posterior crossbite, treated and untreated, in the deciduous dentition-occlusal and skeletal characteristics of significance in predicting the long-term outcome. J OrofacOrthop 63:371-383.
3. Kurol J, Berglund L. (1992) longitudinal study and cost-benefit analysis of the effect of early treatment of posterior cross- CONDYLAR ASYMMETRY IN POSTERIOR CROSSBITE 81 Angle Orthodontist, Vol 77, No 1, 2007 bites in the primary dentition. Eur J Orthod 14:173- 179.

4. Sandikcioglu M, Hazar S. (1997) Skeletal and dental changes after maxillary expansion in the mixed dentition. Am J Orthod Dent of acial Orthop 111:321-327.

5. Kook, Y.-A., et al. (2009) Overjet at the anterior and posterior segments: three-dimensional analysis of arch coordination. The Angle Orthodontist79: 495-501.

6. Kutin, G. and R. R. Hawes (1969) Posterior cross-bites in the deciduous and mixed dentitions. American Journal of Orthodontics 56: 491-504.

7. Ngan, P. W. and S. H. Wei (1990) Treatment of posterior crossbite in the primary and early mixed dentitions. Quintessence international 21.

8. O'Byrn, B. L., et al. (1995) "An evaluation of mandibular asymmetry in adults with unilateral posterior crossbite." American Journal of Orthodontics and Dentofacial Orthopedics $107: 394-400$.

9. Pinto, A. S., et al. (2001) "Morphological and positional asymmetries of young children with functional unilateral posterior crossbite." American Journal of Orthodontics and Dentofacial Orthopedics $120: 513-520$.

10. Uysal, T., et al. (2009) "Condylar and ramal vertical asymmetry in unilateral and bilateral posterior crossbite patients and a normal occlusion sample." American Journal of Orthodontics and Dentofacial Orthopedics 136:37-43.

11. Allen D, Rebellato J, Sheats R, Ceron AM (2003) Skeletal and dental contributions to posterior crossbites. Angle Orthod 73:515-524.

12. Graber TM. Dentofacial orthopedics (1969) In: Graber TM, ed. Current Orthodontics Concepts and Techniques. (2 edn). Philadelphia, Pa: WB Saunders Co 918-988.

13. McNamara JA. (1981) Influence of respiratory pattern on craniofacial growth. Angle Orthod 51:269-300.

\section{Submit your manuscript to a JScholar journal and benefit from:}

- Convenient online submission

9 Rigorous peer review

- Immediate publication on acceptance

I Open access: articles freely available online

I High visibility within the field

ฯ Better discount for your subsequent articles Submit your manuscript at http://www.jscholaronline.org/submit-manuscript.php 